\title{
APORTE DE SERAPILHEIRA E NUTRIENTES EM UMA ÁREA DE CAATINGA
}

\author{
LITTER PRODUCTION AND NUTRIENTS IN AREA OF CAATINGA BIOME
}

\author{
Alan Cauê de Holanda ${ }^{1}$ Ana Lícia Patriota Feliciano ${ }^{2}$ Fernando José Freire ${ }^{3}$ \\ Flaubert Queiroga de Sousa ${ }^{4}$ Saul Ramos de Oliveira Freire ${ }^{5}$ Allyson Rocha Alves ${ }^{1}$
}

\begin{abstract}
RESUMO
A Caatinga é um dos biomas brasileiros no qual se registram os maiores índices de degradação, associada, principalmente, à supressão da vegetação para produção energética e prática da agricultura de subsistência, ocasionando interferências na ciclagem de nutrientes. O objetivo do trabalho foi quantificar e analisar quimicamente a deposição de serapilheira em um fragmento de Caatinga, localizado no município de Pombal - PB. Foi coletada mensalmente, durante 12 meses, e separada em diferentes frações (folhas, estruturas reprodutivas, galhos e miscelânea) toda serapilheira depositada em coletores de $1,0 \mathrm{~m}^{2}$ de área, distribuídas de forma sistemática. Os nutrientes analisados foram $\mathrm{N}, \mathrm{P}, \mathrm{K}, \mathrm{Ca}$ e $\mathrm{Mg}$. A deposição anual de serapilheira foi de $3.785,67 \mathrm{~kg} \mathrm{ha}^{-1}$, composta predominantemente da fração folha com $70,2 \%$, seguida pela fração estruturas reprodutivas com $18,3 \%$. Os teores de nutrientes na serapilheira seguiram a ordem $\mathrm{Ca}>\mathrm{N}>\mathrm{K}>\mathrm{Mg}>\mathrm{P}$. O teor de nutrientes nas frações varia em função do tempo e há evidências de sua relação com a precipitação pluviométrica. A deposição da serapilheira coincidiu com o período de sazonalidade da Caatinga.
\end{abstract}

Palavras-chave: produção de serapilheira; resíduos orgânicos; ciclagem de nutrientes.

\begin{abstract}
Caatinga is one of the Brazilian biomes where the highest degradation rates are recorded. It is associated mainly to the removal of vegetation for energy production and practice of subsistence agriculture, causing interference in nutrient cycling. The aim of the study was to quantify and chemically analyze litter deposition in a fragment of Caatinga, located in the municipality of Pombal, Paraíba (PB) state. It was collected monthly for 12 months, and separated into different fractions (leaves, reproductive structures, branches and miscellaneous), all litter deposited on collectors of $1.0 \mathrm{~m} 2$, distributed systematically. The nutrients analyzed were $\mathrm{N}, \mathrm{P}, \mathrm{K}, \mathrm{Ca}$ and $\mathrm{Mg}$. The annual litter was of $3785.67 \mathrm{~kg} \mathrm{ha}^{-1}$, predominantly composed of leaf fraction with $70.2 \%$, followed by the fraction reproductive structures with $18.3 \%$. The nutrient content in the leaf litter followed the order $\mathrm{Ca}>\mathrm{N}>\mathrm{K}>\mathrm{Mg}>\mathrm{P}$. The nutrient content in the fractions vary according to time and there is evidence of their relationship with the rainfall. The deposition of litter coincided with the seasonal period of Caatinga.
\end{abstract}

Keywords: litter production; organic waste; nutrient cycling.

1 Engenheiro Florestal, Dr., Professor do Departamento de Ciências Vegetais, Universidade Federal Rural do Semi-Árido, Av. Francisco Mota, 572, Bairro Costa e Silva, CEP 59625-900, Mossoró (RN), Brasil. alan.holanda@ufersa.edu.br/ allyson@ufersa.edu.br

2 Engenheira Florestal, Dra., Professora do Departamento de Ciência Florestal, Universidade Federal Rural de Pernambuco, Rua Dom Manoel de Medeiros, s/n, Dois Irmãos, CEP 52171-900, Recife (PE), Brasil. licia@ufrpe.br

3 Engenheiro Agrônomo, Dr., Professor do Departamento de Agronomia, Universidade Federal Rural de Pernambuco, Rua Dom Manoel de Medeiros, s/n, Dois Irmãos, CEP 52171-900, Recife (PE), Brasil. f.freire@depa.ufrpe.br

4 Engenheiro Agrônomo, Doutorando em Agronomia pela Universidade Federal da Paraíba, Departamento de Agronomia, Rodovia BR 079, Km 12, CEP 58397-000, Areia (PB), Brasil. flaubertqueiroga@yahoo.com.br

5 Engenheiro Agrônomo, Mestrando em Horticultura tropical pela Universidade Federal de Campina Grande, Centro de Ciência e Tecnologia Agroalimentar, Rua Jairo Vieira Feitosa, 1770, Bairro dos Pereiros, CEP 58840-000, Pombal (PB), Brasil.saul.ramos@hotmail.com

Recebido para publicação em 25/04/2012 e aceito em 4/08/2015 


\section{INTRODUÇÃO}

A Caatinga cobre uma grande área do semiárido nordestino e parte dela é derrubada anualmente para produção de lenha e para plantio no sistema de agricultura itinerante. Geralmente, nesses locais, após a retirada da madeira aproveitável, o material vegetal é queimado (SAMPAIO et al., 1998), razão pela qual se geram perdas consideráveis de nutrientes.

Nos ecossistemas florestais, as reservas minerais e orgânicas acumulam-se na biomassa vegetal e animal, na serapilheira e no solo (PEREIRA et al., 2008), e intervenções antrópicas comprometem o fluxo de entrada e saída de nutrientes no sistema. Andrade et al. (2008) relataram que a deposição de serapilheira é um dos aspectos da ciclagem de nutrientes mais importantes, pois a nutrição dos vegetais nos ecossistemas, geralmente com baixo conteúdo de nutrientes no solo, depende da ciclagem dos nutrientes contidos na biomassa vegetal.

Para Schumacher et al. (2004), a produção de serapilheira e a devolução de nutrientes em ecossistemas florestais constituem a via mais importante do ciclo biogeoquímico (fluxo de nutrientes no sistema solo-planta-solo). Este ciclo, juntamente com o bioquímico (circulação de nutrientes no interior da planta), permite que as árvores possam sintetizar a matéria orgânica através da fotossíntese, reciclando principalmente os nutrientes em solos, onde a biomassa vegetal pode ser o principal reservatório.

A geração de informações sobre a deposição de serapilheira e análise do seu conteúdo são importantes ferramentas para a compreensão e conservação dessas áreas, bem como suas inter-relações com o meio. Na pesquisa sobre produção de serapilheira, destaca-se a importância desse material na conservação e manutenção natural dos ecossistemas (COSTA et al., 2010).

Vários fatores bióticos e abióticos afetam a produção de serapilheira, tais como: tipo de vegetação, altitude, latitude, precipitação, temperatura, regimes de luminosidade, relevo, deciduidade, estágio sucessional, disponibilidade hídrica, características do solo e dependendo das características de cada ecossistema, um determinado fator pode prevalecer sobre os demais (FIGUEIREDO FILHO et al., 2003).

Diante desse contexto, percebem-se as múltiplas funções positivas que a serapilheira proporciona para o ambiente ecológico e, há uma dinâmica na ciclagem biogeoquímica para os diferentes ecossistemas florestais, que proporciona melhoria nos atributos químicos e físicos do solo, entretanto, acredita-se que, entre as diversas tipologias florestais, existem fatores abióticos intrínsecos influenciando no processo de ciclagem, configurado através de comportamentos distintos de aporte de resíduos vegetais e nutrientes.

Partindo desse princípio e dos benefícios que a serapilheira propicia aos ciclos biogeoquímicos e químicos, como também aos atributos físicos do solo nas mais diversas áreas fitofisionômicas do Brasil, é que o presente estudo objetivou analisar a deposição de serapilheira e o aporte de nutrientes em uma área de Caatinga.

\section{MATERIAL E MÉTODOS}

\section{Caracterização da área}

O estudo foi desenvolvido no Sitio Riachão, localizado no município de Pombal - PB. A área onde foi conduzido o trabalho tem 26,4 ha e encontra-se inserida entre as coordenadas geográficas $6^{\circ} 52^{\prime} 31^{\prime \prime}$ latitude Sul e $37^{\circ} 49^{\prime} 43$ " longitude Oeste.

O município de Pombal situa-se na região oeste do estado da Paraíba, Mesorregião do Sertão Paraibano e Microrregião de Sousa. A área está inserida na unidade geoambiental da depressão sertaneja, que representa a paisagem típica do semiárido nordestino, caracterizada por uma superfície de pediplanação bastante monótona, relevo predominantemente suave-ondulado, cortada por vales estreitos (COMPANHIA DE PESQUISA DE RECURSOS MINERAIS, 2005).

O clima da região é caracterizado como BSh (clima semiárido quente) segundo a classificação de Köppen, com precipitação pluviométrica média anual mensurada nos últimos 10 anos de $963,07 \mathrm{~mm}$ (AGÊNCIA EXECUTIVA DE GESTÃO DAS ÁGUAS DO ESTADO DA PARAÍBA, 2011) e temperatura média de $28^{\circ} \mathrm{C}$. A área encontra-se com altitudes variando entre 200 e $230 \mathrm{~m}$. Os solos são classificados como Luvissolos em associação com Neossolos Litólicos (EMBRAPA, 2006). Os atributos químicos do 
solo são apresentados na Tabela 1 .

TABELA 1: Atributos químicos do solo em uma área de Caatinga, Pombal - PB.

TABLE 1: Soil chemical properties in an area of Caatinga biome, Pombal - PB state.

\begin{tabular}{|c|c|c|c|c|c|c|c|c|c|}
\hline \multirow{2}{*}{$\mathrm{pH} \mathrm{H}_{2} \mathrm{O}$} & \multirow{2}{*}{$\mathrm{P} \mathrm{mg} \mathrm{dm}^{-3}$} & $\mathrm{~K}^{+}$ & $\mathrm{Ca}^{2+}$ & $\mathrm{Mg}^{2+}$ & $\mathrm{Na}^{+}$ & $\mathrm{H}^{+}+\mathrm{Al}^{3+}$ & SB & $\mathrm{T}$ & V \\
\hline & & \multicolumn{7}{|c|}{ 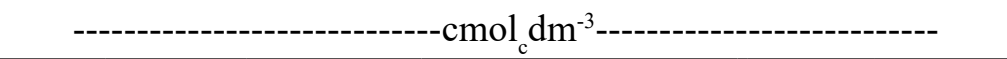 } & $\%$ \\
\hline 5,49 & 3,45 & 0,64 & 6,82 & 3,85 & 0,16 & 0,16 & 11,47 & 11,63 & 98,58 \\
\hline
\end{tabular}

Em que: $\mathrm{P}, \mathrm{K}, \mathrm{Na}$ : extrator Mehlich 1; $\mathrm{Al}, \mathrm{Ca}, \mathrm{Mg}$ : extrator $\mathrm{KCl} 1,0 \mathrm{~mol} \mathrm{~L}^{-1} ; \mathrm{SB}=\mathrm{Ca}^{+2}+\mathrm{Mg}^{+2}+\mathrm{K}^{+}+\mathrm{Na}^{+}$.

Ao consultar o sistema de classificação da vegetação brasileira adaptada ao sistema universal (VELOSO; RANGEL FILHO; LIMA, 1991), a princípio, pode-se considerar o fragmento como savana estépica florestada, pois se observa formação caracterizada por micro e/ou nanofanerófitos com média de até 5,0 metros, ultrapassando excepcionalmente os 7,0 metros de altura, com dominância das espécies Croton blachetianus, Anadenanthera colubrina, Poincianella pyramidalis, Aspidosperma pyrifolium, Commiphora leptophloeos, Amburana cearenses, Myracrodruon urundeuva, Combretum leprosum e Mimosa tenuiflora.

\section{Coleta dos dados da serapilheira}

Foram instaladas quarenta caixas coletoras, de forma sistemática, equidistantes 25 metros entre si no sentido leste-oeste do fragmento (4 colunas contendo 10 caixas/cada).

As caixas coletoras possuíam dimensões de $1,0 \mathrm{~m}^{2}$, com as laterais de tábuas de madeira, com 15,0 $\mathrm{cm}$ de altura e o fundo de tela de náilon com malha de $1,0 \mathrm{~mm}^{2}$, suspensa a $10,0 \mathrm{~cm}$ acima da superfície do solo. Mensalmente, durante o período de um ano (abril de 2010 a março de 2011), foi coletado todo material presente nas caixas coletoras. No laboratório realizou-se a triagem das frações: folhas, estruturas reprodutivas (flores, frutos e sementes), galhos (correspondente às partes lenhosas arbustivo-arbóreas com dimensões menores que $2,0 \mathrm{~cm}$ de diâmetro, mais cascas) e miscelânea (material vegetal que não pode ser determinado e material de origem animal). Posteriormente, o material foi acondicionado em sacos de papel, secados a $65^{\circ} \mathrm{C}$ e moídos para caracterização química.

\section{Análise dos dados da serapilheira}

A produção de serapilheira foi estimada pela seguinte equação matemática: $\mathrm{PAS}=(\mathrm{PS} * 10.000) /$ Ac; Em que: PAS = produção média anual de serapilheira $\left(\mathrm{kg} \mathrm{ha}^{-1} \mathrm{ano}^{-1}\right) ; \mathrm{PS}=$ produção média mensal de serapilheira $\left(\mathrm{kg} \mathrm{ha}^{-1} \mathrm{mês}^{-1}\right) ; 10.000=$ um hectare expresso $\mathrm{em} \mathrm{m}^{2}$; e Ac $=$ área do coletor $\left(\mathrm{m}^{2}\right)$.

Para a caracterização química foram sorteadas 16 caixas, entre as $40 . \mathrm{O} \mathrm{N}$ foi determinado pelo método semimicro-kjeldahl após digestão sulfúrica. A determinação das concentrações de $\mathrm{P}, \mathrm{K}, \mathrm{Ca}$ e $\mathrm{Mg}$ foram realizadas mediante a digestão nítroperclórica (3:1) e leitura por colorimetria de metavanadato para $\mathrm{P}$; fotometria de emissão de chama para $\mathrm{K}$ e espectrofotometria de absorção atômica para $\mathrm{Ca}$ e $\mathrm{Mg}$ (EMBRAPA, 1999; MALAVOLTA, 1989).

O delineamento experimental utilizado para análise da deposição da serapilheira foi em blocos casualizados. As médias obtidas para as variáveis foram comparadas pelo teste de Tukey com nível de significância de 5\%. Para verificar a correlação entre o aporte da serapilheira e a precipitação pluviométrica, aplicou-se a análise de componentes principais e análise de agrupamento, utilizando como medida de similaridade a distância euclidiana para se entender a dinâmica dos teores dos nutrientes nas frações em função dos meses de estudo. A análise foi realizada com base na elaboração de uma matriz com todos os elementos em conjunto, para verificar a dinâmica em função dos meses. Os softwares utilizados foram o Sisvar e Statistic versão 5.3 e 7, respectivamente (FERREIRA, 2010; STATSOFT, 2004). 


\section{RESULTADO E DISCUSSÃO}

\section{Deposição de serapilheira}

A produção de serapilheira foi de $3.785,67 \mathrm{~kg} \mathrm{ha}^{-1}$ (Tabela 2). A fração folha apresentou maior contribuição $(70 \%)$, seguida das estruturas reprodutivas (18\%), galhos $(9 \%)$ e miscelânea $(2 \%)$.

A produção de serapilheira no bioma Caatinga, segundo Costa et al. (2010), varia de 1.500 a 3.500 $\mathrm{kg} \mathrm{ha}^{-1}$ ano $^{-1}$, tanto em florestas arbóreas quanto em arbustivas, sendo esses valores determinados pelas características morfológicas e fisiológicas comuns das plantas que compõem o bioma.

Não diferentemente de outras áreas de Caatinga, verifica-se a fração folha com a maior contribuição na produção de serapilheira, sendo esta uma estratégia das plantas para evitar a perda de água por transpiração. Outros pesquisadores (SANTANA, 2005; ALVES et al., 2006; SOUTO, 2006; ESPIG et al., 2009; LOPES et al., 2009; PAULA et al., 2009) reportam em seus trabalhos a fração folha com maiores taxas de deposição, contribuindo em relação à produção total com 79,9\%, 56,2\%, 63,8\%, 66,9\%, 68\% e $67,3 \%$ respectivamente.

Comparando a deposição ocorrida no presente estudo com outras áreas de Caatinga, observou-se aportes diferenciados, o que a princípio está relacionado com a estrutura da vegetação, em que, na Reserva Particular do Patrimônio Natural no semiárido da Paraíba, Souza (2009), registrou uma média anual de $2.266,89 \mathrm{~kg} \mathrm{ha}^{-1}$. Na mesma RPPN, Alves et al. (2006) estimaram em 10 meses uma deposição de 899,2 kg ha $^{-1}$. Santana e Souto (2011), na Estação Ecológica do Seridó (RN), estimaram a deposição de serapilheira em 2.068,55 kg ha-1 ano $^{-1}$. Na Floresta Nacional de Açu - RN, Costa et al. (2010) calcularam uma taxa de deposição de serapilheira semelhante ao presente trabalho, com $3.384 \mathrm{~kg} \mathrm{ha}^{-1}$ ano ${ }^{-1} \mathrm{em}$ fragmento de vegetação arbóreo e de $2.580 \mathrm{~kg} \mathrm{ha}^{-1}$ ano $^{-1}$ em vegetação arbustiva, tal comportamento pode ser explicado em função das adaptações morfológicas e fisiológicas das plantas.

A deciduidade é característica das espécies lenhosas amostradas no presente estudo. A deposição de folhas é variável, sendo registrados as menores taxas de deposição nos meses de maio, outubro, novembro e dezembro de 2010 e março de 2011 (Figura 1).

Quando começou o período de escassez de água no início de maio de 2010, observou-se que no mês subsequente (junho de 2010) as plantas começaram a perder as folhas, e nesse mesmo mês, é registrada a ocorrência de uma chuva de $63 \mathrm{~mm}$, que posteriormente causa uma diminuição no aporte das folhas no mês de julho, porém, a falta d'água nos dois meses seguidos (julho e agosto), fez com que grande parte das plantas apresentasse queda de folhas no mês de agosto, que apresentou o maior registro de deposição, com $963,28 \mathrm{~kg} \mathrm{ha}^{-1}$.

Para Santana e Souto (2011), na Caatinga, a produção de serapilheira foliar está ligada a dois fatores

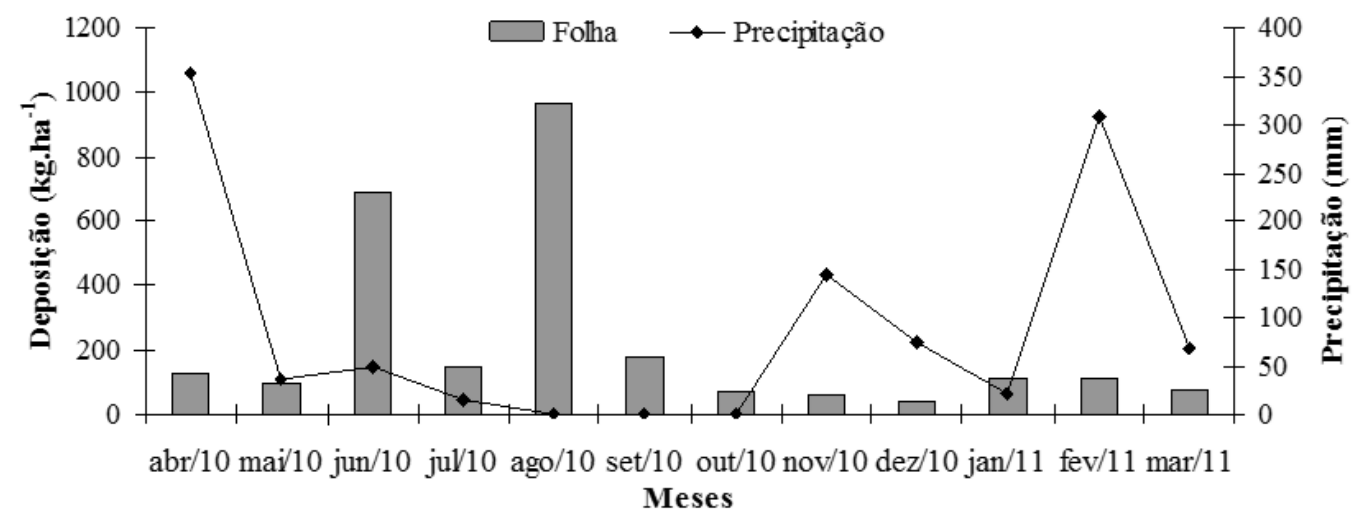

FIGURA 1: Deposição da fração folha da serapilheira e precipitação pluviométrica em área de Caatinga no Sítio Riachão, município de Pombal - PB.

FIGURE 1: Deposition from the leaf fraction of litter and rainfall in an area of Caatinga in the ranch 'Riachão', city of Pombal, PB state. 
TABELA 2: Produção de serapilheira em um remanescente de Caatinga, Pombal - PB.

TABLE 2: Litter production in a remnant of Caatinga, Pombal -PB state.

\begin{tabular}{lcc}
\hline \multicolumn{1}{c}{ Frações } & Biomassa $\left(\mathrm{kg} \mathrm{ha}^{-1} \mathrm{ano}^{-1}\right)$ & Proporção $(\%)$ \\
\hline Estruturas Reprodutivas & 694,26 & 18,34 \\
Folhas & $2.658,33$ & 70,22 \\
Galhos & 352,29 & 9,31 \\
Miscelânea & 80,79 & 2,13 \\
Total & $3.785,67$ & 100 \\
\hline
\end{tabular}

altamente relacionados, que são o início do período seco na área, com redução do teor de umidade no solo, e o caráter caducifólio das espécies, com consequente e imediata abscisão das folhas para reduzir as perdas de água por transpiração. Assim, como algumas espécies da Caatinga mantêm parte das suas folhas durante o ano, mesmo com deficiência hídrica, é provável que o pico de deposição de biomassa foliar decídua logo no início do período seco, seja resultado da perda de folhas das espécies caducifólias, vindo a seguir vários meses com taxas reduzidas de deposição.

A caducifolia da maioria das espécies permite sua sobrevivência nos períodos de seca que sempre assolam a região, em maior ou menor intensidade (SOUTO, 2006). A autora ainda citou que a menor produção de serapilheira no período chuvoso pode ser explicada pela renovação da folhagem, levando a um período fotossinteticamente ativo e à produção e acúmulo de nutrientes para desencadear todos os processos fenológicos ainda no período de maior suprimento hídrico, que na região semiárida é limitado.

A deposição das estruturas reprodutivas apresenta comportamento diferente quando comparada às folhas (Figura 2), estando esse fator relacionado principalmente a eventos fisiológicos e bioquímicos que conduzem à floração em períodos de chuva e estiagem para as diferentes espécies de ocorrência na Caatinga. Para Fisch et al. (2000), a fase reprodutiva corresponde ao período da vida do vegetal mais susceptível às variações nos ambientes e diferentes aspectos, tais como fotoperíodo, umidade, temperatura, polinizadores e dispersores, podem estar envolvidos nas variações apresentadas pelas florações e frutificações de um ano para o outro.

A fração estrutura reprodutiva apresentou deposição de $694,26 \mathrm{~kg} \mathrm{ha}^{-1}$ e coincidentemente, os meses com as menores médias de deposição estão associados aos meses com menores índices pluviométricos, com exceção apenas para o mês maio de 2010 (Figura 2). As maiores médias de deposição foram registradas nos meses de setembro e outubro de 2010 com $161,33 \mathrm{~kg} \mathrm{ha}^{-1}$ e $98,16 \mathrm{~kg} \mathrm{ha}^{-1}$, respectivamente.

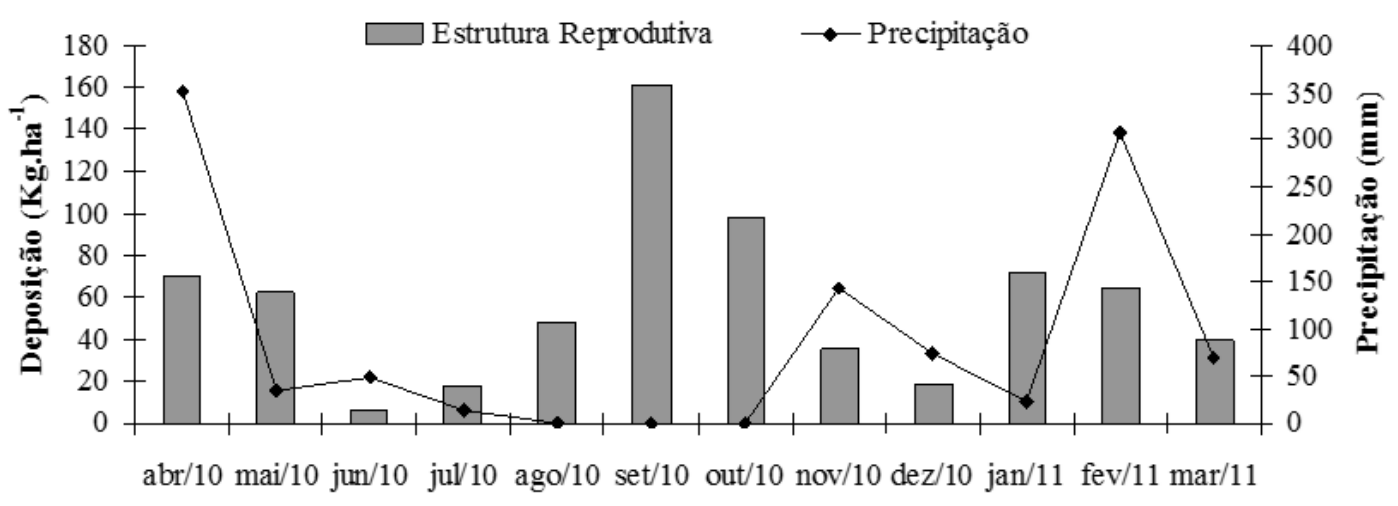

Meses

FIGURA 2: Deposição da fração estrutura reprodutiva da serapilheira e precipitação pluviométrica em área de Caatinga no sítio Riachão, município de Pombal - PB.

FIGURE 2: Deposition fraction of reproductive structure of litter and rainfall in an area of Caatinga in the ranch 'Riachão', city of Pombal, PB state. 
O que confere a alta deposição das estruturas reprodutivas nos meses de setembro e outubro de 2010, diz respeito ao período floração e frutificação intensa da espécie Anadenanthera colubrina (Benth.) Brenan, que se encontra bem distribuída em toda a área e seus frutos estão todos amadurecidos.

De um modo geral, verificou-se que a fração estrutura reprodutiva foi a segunda com maior taxa de deposição (18\%). Andrade et al. (2008) avaliando a deposição de serapilheira em área de caatinga no município de Santa Terezinha - PB, reportaram que a fração estruturas reprodutivas, que incluiu flores, frutos e sementes foi responsável por apenas $8,7 \%$ da produção total da serapilheira.

A literatura reporta padrões distintos de floração e frutificação das espécies arbustivo-arbóreas presentes no Sítio Riachão, algumas apresentando floração na fase de transição chuva-seca e vice-versa, floração e frutificação no período chuvoso, floração e frutificação após perder as folhas, floração na estação chuvosa e frutificação na seca e floração no final da estação seca (MAIA, 2004), podendo essas variações na deposição ser explicada por esses fatores fisiológicos de ciclo reprodutivo das plantas.

Em uma floresta de transição (Floresta tropical úmida e Cerrado), Sanches et al. (2009) constataram que a deposição de flores, mesmo menor que a de folhas, ocorreu somente nos meses de dezembro e janeiro (estação úmida) e a deposição de frutos não apresentaram tendência com relação às condições climáticas, indicando que sua deposição seja possivelmente dependente da estratégia de dispersão adotada pela espécie para sua reprodução e não esteja em função das variações do microclima.

A fração galho foi o terceiro componente com maior taxa de deposição $\left(352,29 \mathrm{~kg} \mathrm{ha}^{-1}\right)$ representando $9,3 \%$ do total. Os meses com as maiores contribuições foram abril e setembro de 2010 e janeiro de 2011, com 67,24; 40,47 e 40,56 $\mathrm{kg} \mathrm{ha}^{-1}$, respectivamente (Figura 3).

Verificou-se uniformidade no aporte desta fração, apesar de terem sido observadas diferenças entre os meses. O mês com a maior deposição foi abril de 2010, e isso pode ter ocorrido por conta de ventos fortes associados à alta precipitação pluviométrica do mês $(352,3 \mathrm{~mm})$, encharcando os galhos secos presos às copas das árvores, tornando-os mais pesados, e mais propensos à ação dos ventos. Essa fração, apesar de contribuir com expressiva biomassa da serapilheira em todos os biomas, é pouco estudada e compreendida, apresentando resultados extremamente variáveis, possivelmente em função da metodologia de coleta utilizada, como o diâmetro mínimo dos galhos e a área dos coletores (SANTANA, 2005).

Para Alves et al. (2006), existe uma grande importância em se estudar o ciclo hidrológico, pois verificaram que, nos meses de outubro, novembro e dezembro a serrapilheira produzida é baixa e a maior contribuição é dada pela fração galhos, devido, provavelmente, à forte ação dos ventos neste período, visto que, como a maioria das espécies que ocorrem na caatinga apresenta caducifolia, pouco ou nenhuma folha se encontra na vegetação. Em floresta estacional decidual, Konig et al. (2002) verificaram que o aporte de quantidades variáveis de queda de galhos podem ser atribuídas à ocorrência de fenômenos climáticos

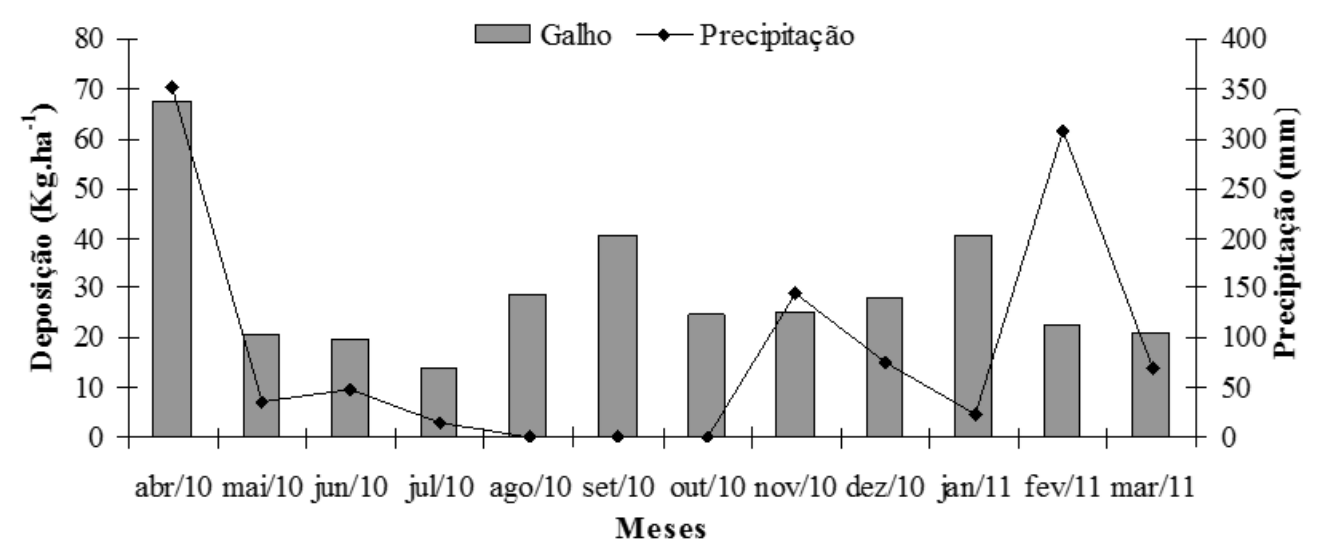

FIGURA 3: Deposição da fração galho da serapilheira e precipitação pluviométrica em área de Caatinga no Sítio Riachão, município de Pombal - PB.

FIGURE 3: Deposition of the fraction of branch litter and rainfall in an area of Caatinga in the ranch 'Riachão', city of Pombal, PB state. 
adversos, como tempestades com ventos anormais, como também, esse fato pode ser explicado pelo menor tamanho da área amostral (coletor), pouco apropriado para a coleta dessa fração.

Dentre as quatro frações, a miscelânea foi a de menor proporção com $80,79 \mathrm{~kg} \mathrm{ha}^{-1}$ referente a $2,1 \%$ de toda a serapilheira. A miscelânea teve altos picos de deposição em abril, junho e novembro de 2010, totalizando $58 \%$ do total da fração, com grande discrepância entre o valor máximo $\left(22,12 \mathrm{~kg} \mathrm{ha}^{-1}\right)$ e mínimo $\left(1,23 \mathrm{~kg} \mathrm{ha}^{-1}\right)$ de deposição (Figura 4). Vale ressaltar, que essa fração representada no estudo, compreende todo material depositado nas caixas coletoras de difícil identificação, que vão além dos próprios resíduos vegetais bastante fragmentados, a insetos, partes destes, fezes, dentre outros.

Os $2 \%$ da serapilheira correspondente à fração miscelânea encontrados nesse trabalho representam mais que as proporções calculadas por Andrade et al. (2008) de 0,78\% e Souto (2006) com 1,46\% da serapilheira total depositada, e inferior ao constatado por Santana (2005), que encontrou 7,9\%.

Apesar das irregularidades no padrão de distribuição dessa fração ao longo dos meses, não se pode afirmar que o fator sazonalidade tenha influência direta em sua distribuição. Fernandes e Scaramuzza (2007) em uma área de Savana Arbórea Densa, observaram que a variação temporal da queda de miscelânea foi irregular, não apresentando padrão sazonal, ou seja, apresentou maiores deposições nos meses de setembro, outubro e julho para a floresta nativa, e na capoeira a maior produção se deu nos meses de novembro e fevereiro.

Para Santana (2005), em grande parte dos trabalhos relativos à produção de serapilheira, a fração miscelânea é composta de fragmentos de folhas, galhos, ramos, flores, frutos, sementes e outros materiais vegetais de difícil identificação, além de insetos ou partes destes e fezes, e em seu trabalho, esta fração foi composta em grande parte por penas de pássaros, corpos e fezes. Schumacher et al. (2003) em um povoamento de Acácia mearnsii, quantificaram a deposição de fezes de lagartas ao observar uma alta contribuição dessa fração na serapilheira, que era de $14 \%$ e isso ocorria no verão, período de maior consumo de folhagem pelas lagartas.

Para analisar a correlação entre a deposição das frações que compõem a serapilheira e a precipitação pluviométrica, utilizou-se a análise de componentes principais, e verificou-se que os dois primeiros componentes principais apresentaram acumulação de $72,66 \%$ da variação total. A Figura 5 representa 0 círculo de correlação unitário com as variáveis.

Ao analisar os dados de correlação da serapilheira com a variável suplementar (precipitação), verificou-se que apenas as frações galho e miscelânea encontraram-se significativas com 0,63 e 0,62 , respectivamente, ao nível de $\mathrm{p}<0,05$ e para as demais, as correlações foram $-0,25$ para a componente folha

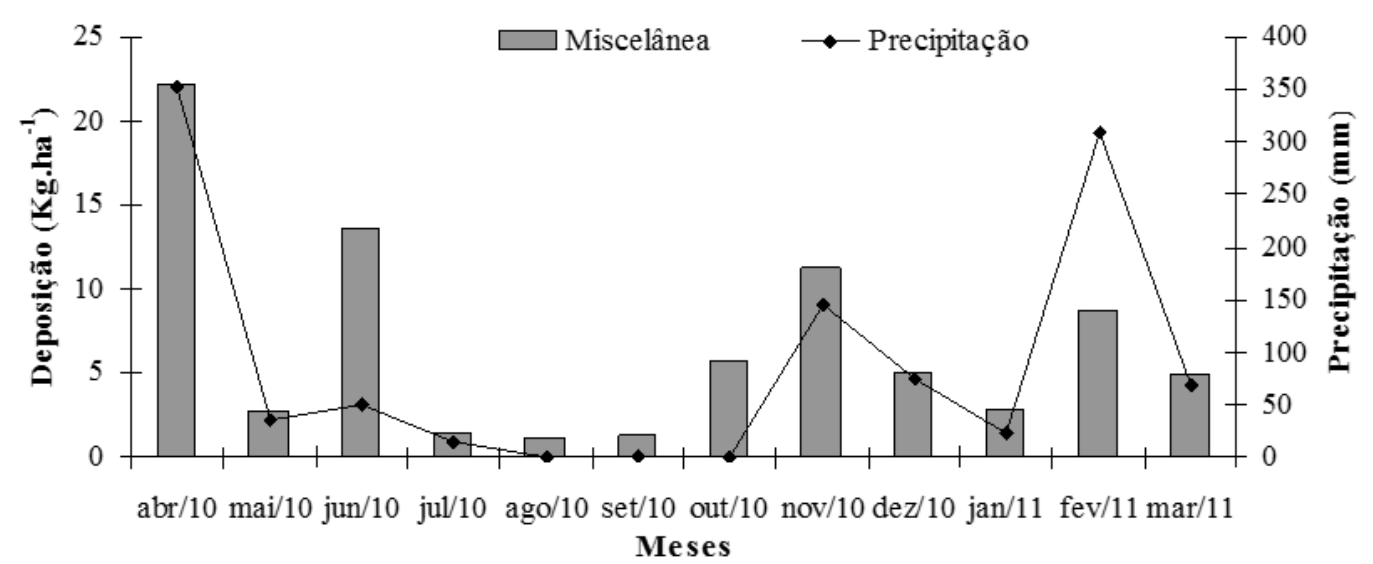

FIGURA 4: Deposição da fração miscelânea da serapilheira e precipitação pluviométrica em área de Caatinga no Sítio Riachão, município de Pombal - PB.

FIGURE 4: Deposition fraction of miscellaneous litter and rainfall in an area of Caatinga in the ranch 'Riachão' Caatinga, city of Pombal, PB state. 
e 0,14 para estruturas reprodutivas.

Pelo fato das variáveis miscelânea e galho encontrarem-se presentes no mesmo quadrante da variável suplementar (precipitação), pode-se constatar a existência de uma correlação positiva entre ambas, ou seja, o fator chuva demonstra uma maior interação na contribuição do aporte dessas frações, o que ocorre diferentemente para a fração folha por estar presente em quadrante oposto, consequentemente, uma correlação negativa, na qual foi observado que em períodos com escassez de chuva existiu uma maior taxa de deposição. Para estrutura reprodutiva, verificou-se uma correlação positiva, porém, baixa, estando isso relacionado principalmente com os processos fisiológicos das plantas que encontram distinções entre os períodos de floração e frutificação.

\section{Deposição de nutrientes}

Na Tabela 3 pode-se verificar que o maior e menor teor de nitrogênio e potássio foi verificado na fração estrutura reprodutiva e galho com 15,61; 9,36; 7,33 e 3,18 $\mathrm{g} \mathrm{kg}^{-1}$ respectivamente. O fósforo apresentou maior teor na fração folha $\left(1,91 \mathrm{~g} \mathrm{~kg}^{-1}\right)$ e menor no galho $0,92 \mathrm{~g} \mathrm{~kg}^{-1}$. O teor de Ca é maior na folha e galho com 21,86 e 16,56 $\mathrm{g} \mathrm{kg}^{-1}$, respectivamente. Para o $\mathrm{Mg}$ verificou-se na fração folha (3,23 $\left.\mathrm{g} \mathrm{kg}^{-1}\right)$, seguido de Miscelânea $\left(2,23 \mathrm{~g} \mathrm{~kg}^{-1}\right)$, estrutura reprodutiva $\left(1,70 \mathrm{~g} \mathrm{~kg}^{-1}\right)$ e galho com $1,13 \mathrm{~g} \mathrm{~kg}^{-1}$.

$\mathrm{O}$ teor inferior de $\mathrm{N}$ nas folhas, quando comparado às estruturas reprodutivas e miscelânea, a princípio está relacionado com a senescência, pois, segundo Morenco e Lopes (2011), o elemento é facilmente translocável, e quando as folhas se tornam amarelo-pardas e logo senescem, as folhas novas permanecem verdes, pois formas solúveis do $\mathrm{N}$ são retranslocadas das mais velhas.

Para o K, os maiores teores observados foram nas estruturas reprodutivas $\left(7,33 \mathrm{~g} \mathrm{~kg}^{-1}\right)$. Conforme citam Shumacher et al. (2003), as concentrações maiores do K nas estruturas reprodutivas se devem ao fato de ser um elemento altamente móvel no floema e prontamente redistribuído para os órgãos novos em crescimento, sendo uma de suas funções proteger a planta contra doenças, além de auxiliar na manutenção dos frutos.

O Ca teve os maiores teores observados em relação aos demais nutrientes, com o componente folha apresentando os maiores valores (21,86 $\left.\mathrm{g} \mathrm{kg}^{-1}\right)$ e, para Dias et al. (2002), o teor de Ca tende a apresentar uma maior variação com picos positivos durante os meses mais secos, provavelmente por haver uma menor taxa metabólica neste período, o que reduziria ainda mais a mobilidade deste elemento que é considerado pouco móvel. Isto faz com que o Ca, mesmo em excesso, armazenado em forma de cristais na folha, permaneça nela mesmo na sua senescência.

Os elementos que estão em maiores concentrações na serapilheira, e que irão retornar ao solo obedecem a seguinte ordem: $\mathrm{Ca}>\mathrm{N}>\mathrm{K}>\mathrm{Mg}>\mathrm{P}$. Esse resultado é semelhante ao observado por Santana (2005) em área de Caatinga na Estação Ecológica do Seridó do Rio Grande do Norte, com a mesma sequência de retorno, porém, com concentrações diferentes. Quando comparados com o trabalho de Souto (2006), perceberam-se diferenças na sequência do retorno: $\mathrm{N}>\mathrm{Ca}>\mathrm{S}>\mathrm{K}>\mathrm{Mg}>\mathrm{P}$, estando o retorno de nutrientes através da serapilheira bem abaixo ao observado no presente trabalho.

TABELA 3: Teor médio de nutrientes nas frações da serapilheira em remanescente de Caatinga, Pombal - PB.

TABLE 3: Average content of nutrients in litter in remaining fractions of Caatinga, Pombal -PB state.

\begin{tabular}{lccccc}
\hline \multirow{2}{*}{ Frações } & $\mathrm{N}$ & $\mathrm{P}$ & $\mathrm{K}$ & $\mathrm{Ca}$ & $\mathrm{Mg}$ \\
\cline { 2 - 6 } & & $-1,91$ & 5,47 & 21,86 & 3,23 \\
\hline Folha & 11,98 & 1,74 & 7,33 & 7,96 & 1,70 \\
E. Reprodutiva & 15,61 & 0,92 & 3,18 & 16,56 & 1,13 \\
Galho & 9,36 & 1,87 & 5,80 & 9,86 & 2,23 \\
Miscelânea & 13,85 & & & \\
\hline
\end{tabular}


Os resultados levantados no presente trabalho, diferiram dos observados por Souto et al. (2009) em área de Caatinga, em que os autores constataram que o nutriente em maior concentração na serapilheira foi o $\mathrm{N}$ e o gradiente de concentração dos nutrientes apresentou a seguinte ordem: $\mathrm{N}>\mathrm{Ca}>\mathrm{S}>\mathrm{K}>\mathrm{Mg}>\mathrm{P}$. Santana (2005), em uma área de Caatinga localizada no Seridó do Rio Grande do Norte, constatou a mesma sequência da concentração de nutrientes observada no presente trabalho $(\mathrm{Ca}>\mathrm{N}>\mathrm{K}>\mathrm{Mg}>\mathrm{P})$, porém, com valores mais altos.

Souto et al. (2009) atribuíram essas variações à presença de espécies diferentes, com idades diferentes e, também, às alterações nas condições edafoclimáticas, apesar de ser em área de Caatinga. Para Schumacher et al. (2004), a concentração de nutrientes na serapilheira pode variar, para uma mesma espécie, em função do sítio, das características da planta e das do próprio elemento.

Sequência semelhante ao presente trabalho, no que diz respeito à concentração de nutrientes na serapilheira foi observado por Cunha et al. (1993), em floresta estacional decidual: $\mathrm{Ca}>\mathrm{N}>\mathrm{K}>\mathrm{Mg}>\mathrm{P}$. Gomes et al. (2010), em fragmento de Mata Atlântica no Rio de Janeiro, observaram a seguinte ordem de concentração de nutrientes via serapilheira: $\mathrm{Ca}>\mathrm{K}>\mathrm{Mg}>\mathrm{P}$. Também em fragmento de Mata Atlântica, Dickow (2010) verificou que as concentrações dos elementos variou na seguinte ordem: $\mathrm{N}>\mathrm{Ca}>\mathrm{K}>\mathrm{Mg}>$ $\mathrm{P}>\mathrm{Na}$. Em área de floresta estacional semidecidual no interior de São Paulo, Vital et al. (2004) verificaram para $\mathrm{N}$ uma concentração de 21,58 $\mathrm{g} \mathrm{kg}^{-1}, \mathrm{P} 1,37 \mathrm{~g} \mathrm{~kg}^{-1}, \mathrm{~K} 6,23 \mathrm{~g} \mathrm{~kg}^{-1}, \mathrm{Ca} 22,85 \mathrm{~g} \mathrm{~kg}^{-1}$ e Mg 4,4 $\mathrm{g} \mathrm{kg}^{-1}$. Já Pinto et al. (2009), em dois trechos de floresta estacional semidecidual, verificaram concentrações médias para N, P, K, Ca e Mg de 19,9; 0,92; 2,27; 14,13; $2,63 \mathrm{~g} \mathrm{~kg}^{-1}$, respectivamente.

Para plantios homogêneos no município de Cambará do Sul - RS, Schumacher et al. (2008), analisando a transferência de nutrientes em uma área de floresta de Pinus entre o quinto e sétimo ano de idade, observaram que a magnitude de transferência de nutrientes ao solo do povoamento foi: $\mathrm{Ca}>\mathrm{N}>\mathrm{Mg}$ $>\mathrm{K}>\mathrm{S}>\mathrm{P}$ e os teores de $\mathrm{P}, \mathrm{K}$ e Mg foram bastante baixos, devido à baixa disponibilidade desses elementos no solo em consequência da elevada acidez. Em uma área de taxi-branco (Sclerolobium paniculatum) e floresta secundaria no Amapá, Mochiutti et al. (2006) reportam uma concentração dos elementos na seguinte ordem: $\mathrm{N}>\mathrm{Ca}>\mathrm{Mg}>\mathrm{K}>\mathrm{P}$. Em uma mata não minerada e em plantações de bracatinga e eucalipto em áreas de mineração de bauxita, Souza e Davide (2001) descrevem que as concentrações de nutrientes que poderiam retornar ao solo, podem fazê-lo de acordo com duas sequências: $\mathrm{Ca}>\mathrm{N}>\mathrm{Mg}>\mathrm{K}>\mathrm{P}$ para a mata não minerada e eucalipto, e $\mathrm{N}>\mathrm{Ca}>\mathrm{Mg}>\mathrm{K}>\mathrm{P}$ para a bracatinga. Em povoamento de acácia-negra, Viera e Schumacher (2010) descrevem as seguintes concentrações na serapilheira, $\mathrm{N}\left(17,88 \mathrm{~g} \mathrm{~kg}^{-1}\right), \mathrm{P}(0,71$ $\left.\mathrm{g} \mathrm{kg}^{-1}\right), \mathrm{K}\left(4,83 \mathrm{~g} \mathrm{~kg}^{-1}\right), \mathrm{Ca}\left(4,71 \mathrm{~g} \mathrm{~kg}^{-1}\right)$ e $\mathrm{Mg}\left(1,8 \mathrm{~g} \mathrm{~kg}^{-1}\right)$.

Sobre as quantidades de nutrientes que retornam ao solo da Caatinga no Sítio Riachão, verifica-se que os elementos $\mathrm{Ca}$, $\mathrm{Ne} \mathrm{K}$ apresentam os maiores valores com 70,30; 47,09 e 21,26 $\mathrm{kg} \mathrm{ha}^{-1}$, respectivamente, seguidos do $\mathrm{P}\left(6,79 \mathrm{~kg} \mathrm{ha}^{-1}\right)$ e $\mathrm{Mg}\left(10,36 \mathrm{~kg} \mathrm{ha}^{-1}\right)$ (Tabela 4).

Uma das hipóteses que justificaria o maior retorno do elemento $\mathrm{Ca}$ ao solo via serapilheira, quando comparado aos demais, pode estar relacionado com o solo, pois se verificou um alto teor desse elemento, consequentemente proporcionando ao longo do tempo um maior acúmulo de nutrientes nas plantas e, pelo fato do $\mathrm{Ca}$ ser um elemento estruturante, apresentar-se com baixíssima mobilidade no ciclo bioquímico, algumas estruturas das plantas vão senescer, posteriormente depositando-se sobre a superfície do solo. $\mathrm{O} \mathrm{N}$ foi o segundo nutriente a ser fornecido em maior quantidade, e isto está relacionado a princípio, a presença de espécies leguminosas, uma vez que as mesmas atuam como importantes rotas na fixação de $\mathrm{N}$ atmosférico.

Dentre os 5 elementos analisados, o $\mathrm{P}$ e $\mathrm{Mg}$ encontra-se com as menores contribuições e, para o $\mathrm{P}$, isso pode estar relacionado ao fato dos solos da Caatinga, principalmente para essa área, terem baixos teores desse elemento. Já o Mg pode ser explicado porque, conforme descrito por Morenco e Lopes (2011), ele é absorvido em quantidade menor que o $\mathrm{Ca}$ e o $\mathrm{K}$, e é um elemento facilmente translocado dos tecidos velhos para os mais novos, o que seria umas das justificativas para as menores aportes.

Há uma série de fatores abióticos e bióticos que influenciam e interferem na quantidade de nutrientes que retornam ao solo vai serapilheira em diferentes ecossistemas e, isso é muito relativo, conforme pode ser verificado no trabalho realizado por Espig et al. (2009) em um Fragmento de Floresta Ombrófila Densa urbano, na região de Recife - PE, onde quantificaram apenas para o componente folha, o retorno para $\mathrm{P}$, $\mathrm{K}, \mathrm{Ca}$ e Mg de 2,7; 29,1; 118,0 e 18,4 $\mathrm{kg} \mathrm{ha}^{-1}$, respectivamente. Em Floresta Ombrófila Mista Montana no 
TABELA 4: Conteúdo de nutrientes que retornam ao solo em um remanescente de Caatinga no município de Pombal - PB.

TABLE 4: Nutrient content returning to the ground in a remnant of Caatinga, in the municipality of Pombal -PB state.

\begin{tabular}{|c|c|c|c|c|c|}
\hline \multirow{2}{*}{ Frações } & $\mathrm{N}$ & $\mathrm{P}$ & K & $\mathrm{Ca}$ & $\mathrm{Mg}$ \\
\hline & \multicolumn{5}{|c|}{---------------------------kg ha'-1-------------------------- } \\
\hline Folha & 31,84 & 5,10 & 14,57 & 58,12 & 8,60 \\
\hline E. Reprodutiva & 10,84 & 1,21 & 5,09 & 5,52 & 1,18 \\
\hline Galho & 3,29 & 0,33 & 1,13 & 5,86 & 0,40 \\
\hline Miscelânea & 1,12 & 0,15 & 0,47 & 0,80 & 0,18 \\
\hline Total & 47,09 & 6,79 & 21,26 & 70,30 & 10,36 \\
\hline
\end{tabular}

Paraná, Caldeira et al. (2007) calcularam um retorno para $\mathrm{N}$ equivalente a 95,66 kg ha ${ }^{-1}, \mathrm{P} 5,43 \mathrm{~kg} \mathrm{ha}^{-1}, \mathrm{~K}$ 45,32 $\mathrm{kg} \mathrm{ha}^{-1}$, Ca 36,84 $\mathrm{kg} \mathrm{ha}^{-1}$ e Mg 7,56 kg ha'. Mochiutti et al. (2006) em um Fragmento de Floresta Ombrófila Densa secundária no Amapá, calcularam o retorno de nutrientes via serapilheira de $51,4 \mathrm{~kg} \mathrm{ha}^{-1}$ para N, 2,1 kg ha-1 P, 6,6 $\mathrm{kg} \mathrm{ha}^{-1} \mathrm{~K}, 41,3 \mathrm{~kg} \mathrm{ha}^{-1} \mathrm{Ca}$ e 10,5 $\mathrm{kg} \mathrm{ha}^{-1}$ para o $\mathrm{Mg}$.

Para plantios homogêneos de Eucalyptus urophylla e Eucalyptus globulus, e Acacia mearnsii, Vieira et al. (2014) e Vieira e Schumacher (2010) reportam uma média de retorno de nutrientes via serapilheira para N, P, K, Ca e Mg na ordem de 43,6; 2,3; 18,6; 52,4 e $14 \mathrm{~kg} \mathrm{ha}^{-1}$ e 74,8; 2,4; 18,5; 23,1 e 7,9 kg ha respectivamente. Em um bosque de Mimosa caesalpiniifolia com 17 anos de implantação, localizado na região de Itambé - PE, Ferreira et al. (2007) quantificaram um retorno de nutrientes ao solo via serapilheira de N 156,7 kg ha-1 , P 10,4 kg ha' $\mathrm{kg}^{-1} 4,9 \mathrm{~kg} \mathrm{ha}^{-1}$, Ca 114,8 $\mathrm{kg} \mathrm{ha}^{-1}$ e Mg 26,3 kg ha-1.

Ao analisar a divisão dos meses entre teores dos nutrientes (N, P, K, Ca e Mg) das quatro frações,

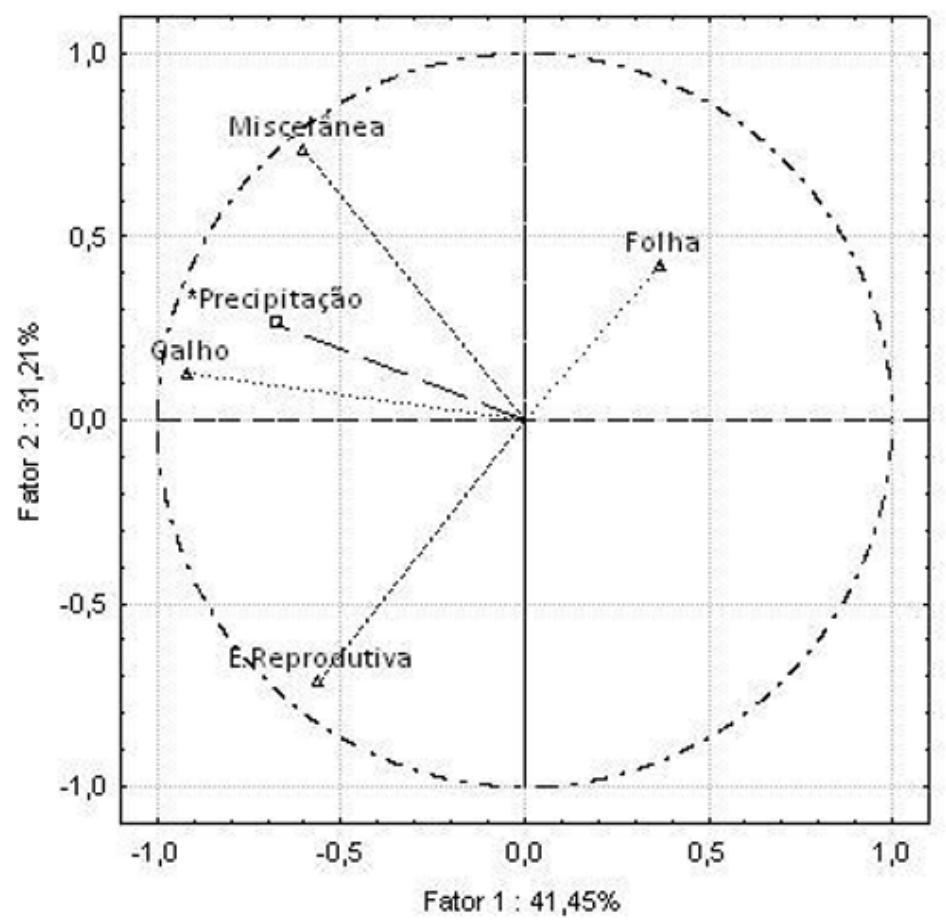

FIGURA 5: Análise de componentes principais para as variáveis da serapilheira com uma variável suplementar num plano de projeção fatorial 1 x 2 .

FIGURE 5: Principal component analysis for the variables of the litter with a variable in a further projection plane 1 x 2 factorial design. 
pode-se verificar que os mesmos encontram-se distintos, com a formação de dois grupos (Figura 6). O primeiro grupo refere-se aos meses de abril, junho, maio, julho e agosto de 2010, o que corresponde aos meses iniciais de instalação, e apresentou um regime pluviométrico acumulado de $451,6 \mathrm{~mm}$, e um segundo grupo formado pelos demais meses, com um regime de chuva acumulado em 617,6 mm.

Avaliando o dendrograma, percebe-se que os teores e distribuições dos nutrientes ao longo dos meses têm relações com algum fator abiótico que influenciou nos processos bioquímicos e fisiológicos das plantas. Isso pode estar relacionado com o baixo conteúdo de água no solo, pelo fato do mesmo ser raso, refletindo em uma redução na quantidade de água infiltrada, pois, quando comparadas as chuvas acumuladas para os dois grupos, verificou-se que no primeiro grupo, o regime pluviométrico foi menor que o segundo, o que, a princípio, em concomitância, influenciou em uma baixa absorção dos nutrientes e no aumento da retranslocação dos mesmos para outros compartimentos da planta, desta forma, acumulando-se em menores proporções nas estruturas senescentes.

É válido ressaltar que a estrutura da vegetação, temperatura e luz também são outros fatores que têm influência na mobilidade dos nutrientes, o que pode ocasionar a distribuição irregular dos elementos, conferindo médias de teores menores nos meses de abril a agosto de 2010.

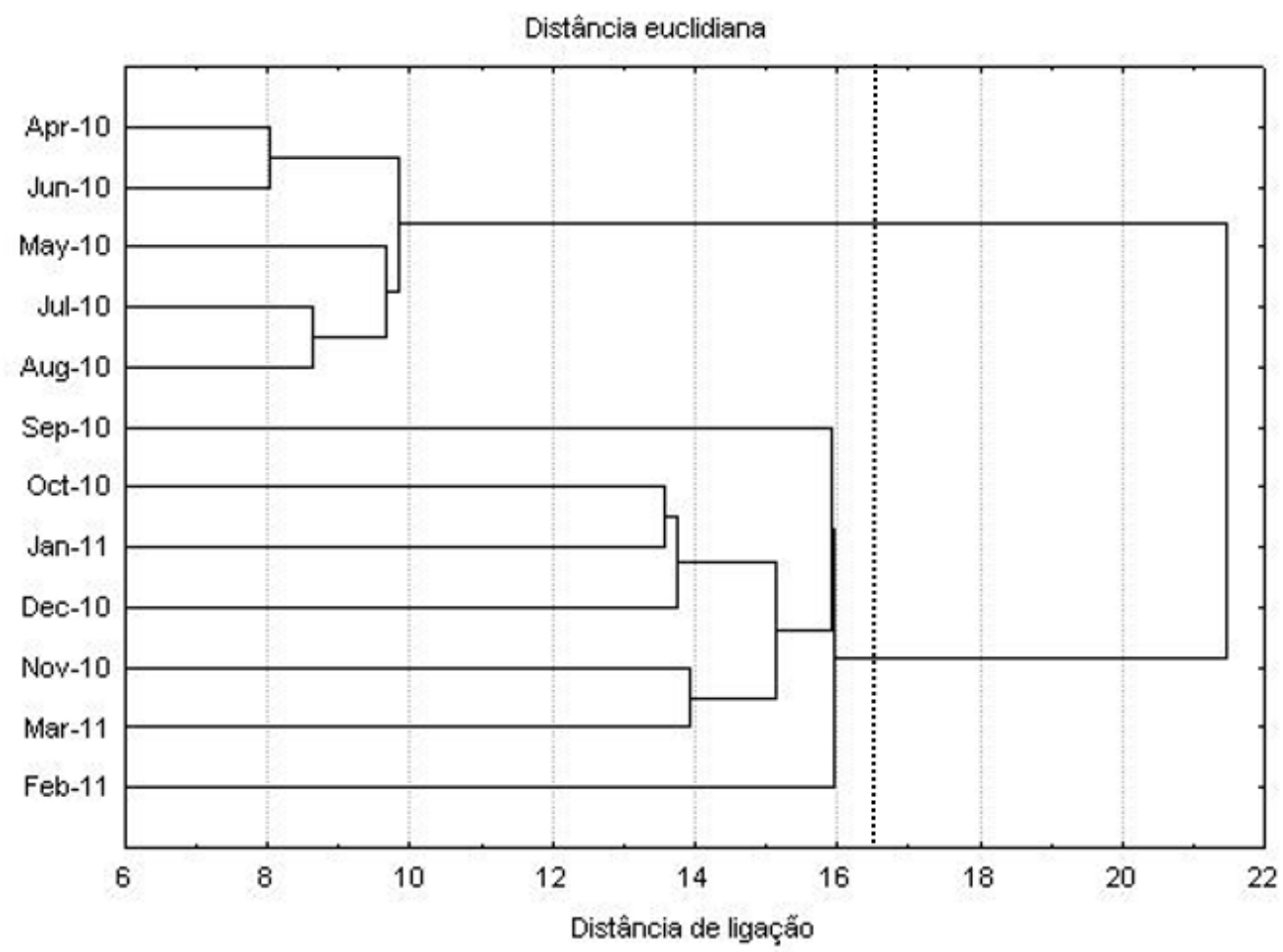

FIGURA 6: Dendrograma pelo método de ligações simples, que representa a relação entre a distribuição dos meses em função das concentrações dos nutrientes $\mathrm{N}, \mathrm{P}, \mathrm{K}, \mathrm{Ca}$ e $\mathrm{Mg}$ em área de Caatinga no Sítio Riachão, município de Pombal - PB.

FIGURE 6: Dendrogram by the method of single bonds, which represents the relationship between the distribution of months depending on the concentrations of $\mathrm{N}, \mathrm{P}, \mathrm{K}, \mathrm{Ca}$ and $\mathrm{Mg}$ in an area of Caatinga in the ranch 'Riachão', city of Pombal, PB state.

\section{CONCLUSÕES}

A deposição da serapilheira para essa área de Caatinga é superior a outras regiões do bioma e, inferior a outros ecossistemas florestais e plantios homogêneos. Apresenta comportamento sazonal, com maior deposição em períodos de escassez hídrica;

O componente folha foi o maior contribuinte na produção total da serapilheira e sua deposição em 
maiores proporções está diretamente relacionado ao ajustamento das plantas em evitar a perda de água por transpiração em períodos adversos;

Os meses em que se verificaram baixos índices pluviométricos coincidem com o período em que se registrou baixos teores de nutrientes na serapilheira.

\section{REFERÊNCIAS}

AGÊNCIA EXECUTIVA DE GESTÃO DAS ÁGUAS DO ESTADO DA PARAÍBA. Monitoramento de chuvas acumuladas. Disponível em: $<\mathrm{http}: / / \mathrm{http}: / /$ site2.aesa.pb.gov.br/aesa/monitoramentoPluviometria. do?metodo=listarChuvasAnuaisAtual>. Acesso em: 4 abr. 2011.

ALVES, A. R. et al. Aporte e decomposição de Serapilheira em área de Caatinga, na Paraíba. Revista de Biologia e Ciências da Terra, São Cristóvão, v. 6, n. 2, p. 194-203, 2006.

ANDRADE, R. L. et al. Deposição de Serapilheira em área de Caatinga na RPPN "Fazenda Tamanduá", Santa Terezinha - PB. Revista Caatinga, Mossoró, v. 21, n. 2, p. 223-230, 2008.

CALDEIRA, M. V. W. et al. Quantificação de serapilheira e de nutrientes - Floresta Ombrófila Mista Montana - Paraná. Revista Acadêmica, Curitiba, v. 5, n. 2, p. 101-116, 2007.

COSTA, C. C. A. et al. Análise comparativa da produção de serapilheira em fragmentos arbóreos e arbustivos em área de caatinga na flona de Açu-RN. Revista Árvore, Viçosa, MG, v. 34, n. 2, p. 259-265, 2010.

COMPANHIA DE PESQUISADE RECURSOS MINERAIS. Projeto cadastro de fontes de abastecimento por água subterrânea. Diagnóstico do município de Pombal, estado da Paraíba. Recife: CPRM/PRODEEM, 2005. $23 \mathrm{p}$.

CUNHA, G. C. et al. Dinâmica nutricional em floresta estacional decidual com ênfase aos minerais provenientes da deposição da serapilheira. Ciência Florestal, Santa Maria, v. 3, n. 1, p. 35-64, 1993.

DIAS, H. C. T. et al. Variação temporal de nutrientes na serapilheira de um fragmento de floresta estacional semidecidual montana em Lavras, MG. Cerne, Lavras, v. 8, n. 2, p. 1-16, 2002.

DICKOW, K. M. C. Ciclagem de fitomassa e nutrientes em sucessão secundária na Floresta Atlântica, Antonina, PR. 2010. 215 f. Tese (Doutorado em Engenharia Florestal) - Universidade Federal de Paraná, Curitiba, 2010.

EMBRAPA. Manual de análises químicas de solos, plantas e fertilizantes. Brasília: Embrapa, Comunicação para transferência de tecnologia, 1999. 370 p.

ESPIG, S. A. et al. Sazonalidade, composição e aporte de nutrientes da serapilheira em fragmento de Mata Atlântica. Revista Árvore, Viçosa, MG, v. 33, n. 5, p. 949-956, 2009.

FERREIRA, D. F. SISVAR - Sistema de análise de variância. Versão 5.3. Lavras, MG: UFLA, 2010.

FIGUEIREDO FILHO, A. et al. Avaliação estacional da deposição em uma floresta ombrófila mista localizada no sul do Estado do Paraná. Ciência Florestal, Santa Maria, v. 13, n. 1, p. 11-18, 2003.

FISCH, S. T. V. et al. Fenologia reprodutiva de Euterpe edulis Mart. na Mata Atlântica (Reserva Ecológica do Trabiju, Pindamonhangaba - SP). Revista Biociências, Taubaté, v. 6, n. 2, p. 31-37, 2000.

GOMES, J. M. et al. Aporte de serapilheira e de nutrientes em fragmentos florestais da Mata Atlântica, RJ.

Revista Brasileira de Ciências Agrárias, Recife, v. 5, n. 3, p. 383-391, 2010.

KÖNIG, F. G. et al. Avaliação da sazonalidade da produção de serapilheira numa floresta estacional decidual no município de Santa Maria-RS. Revista Árvore, Viçosa, MG, v. 26, n. 4, p. 429-435, 2002.

LOPES, J.F. B. et al. Deposição e decomposição de serapilheira em área da Caatinga. Revista Agroambiente, Boa Vista, v. 3, n. 2, p. 72-79, 2009.

MAIA, G. N. Caatinga, árvores e arbustos e suas utilidades. São Paulo: D\&Z, 2004. 413 p.

MALAVOLTA, E. Avaliação do estado nutricional das plantas: princípios e aplicações. Piracicaba: Associação Brasileira para Pesquisa do Potassa e do Fosfato, 1989. 201 p.

MOCHIUTTI, S. et al. Produção de serapilheira e retorno de nutrientes de um povoamento de Táxi Branco e de uma floresta secundária no Amapá. Boletim de Pesquisa Florestal, Colombo, v. 52, p. 3-20, 2006.

MORENCO, R. A.; LOPES, N. F. Nutrição Mineral. In: FISIOLOGIA VEGETAL. Viçosa, MG: Editora UFV, 2011. p. 248-326.

PAULA, R. R. et al. Aporte de nutrientes e decomposição da serapilheira em três fragmentos florestais periodicamente inundados na ilha da Marambaia, RJ. Ciência Florestal, Santa Maria, v. 19, n. 2, p. 139- 
148, 2009.

PEREIRA, M. G. et al. Aporte e decomposição da serapilheira na Floresta Atlântica, Ilha da Marambaia, Mangaratiba, RJ. Ciência Florestal, Santa Maria, v. 18, n. 4, p. 443-454, 2008.

PINTO, S. I. C. et al. Ciclagem de nutrientes em dois trechos de floresta estacional semidecidual na reserva florestal Mata do Paraíso em Viçosa, MG, Brasil. Revista Árvore, Viçosa, MG, v. 33, n. 4, p. 653-663, 2009.

SAMPAIO, E. V. S. B.et al. Regeneração da vegetação de caatinga após corte e queima, em Serra Talhada, PE. Pesquisa Agropecuária Brasileira, Brasília, v. 33, n. 5, p. 621-632, 1998.

SANCHES, L. et al. Dinâmica sazonal da produção e decomposição de Serapilheira em floresta tropical de transição. Revista Brasileira de Engenharia Agrícola e Ambiental, Campina Grande, v. 13, n. 2, p. 183-189, 2009.

SANTANA, J. A. S. Estrutura fitossociológica, produção de serapilheira e ciclagem de nutrientes em uma área de Caatinga no Seridó do Rio Grande do Norte. 2005. 206 f. Tese (Doutorado em Agronomia) - Universidade Federal da Paraíba, Areia, 2005.

SANTANA, J. A. S.; SOUTO, J. S. Produção de serapilheira na Caatinga da região semiárida do Rio Grande do Norte, Brasil. Idesia, Arica, v. 29, n. 2, p. 87-94, 2011.

SCHUMACHER, M. V. et al. Retorno de nutrientes via deposição de serapilheira em um povoamento de acácia-negra (Acacia mearnsii de wild.) no estado do Rio Grande do Sul. Revista Árvore, Viçosa, MG, v. 27, n. 6, p. 791-798, 2003.

SCHUMACHER, M. V. et al. Produção de serapilheira em uma floresta de Araucaria angustifolia (Bertol.) Kuntze no município de Pinhal Grande-RS. Revista Árvore, Viçosa, MG, v. 28, n. 1, p. 29-37, 2004.

SCHUMACHER, M. V. et al. Produção de serapilheira e transferência de nutrientes em área de segunda rotação com floresta de Pinus taeda 1. no município de Cambará do Sul, RS. Ciência Florestal, Santa Maria, v. 18, n. 4, p. 471-480, 2008.

SOUTO, P. C. Acumulação e decomposição da serapilheira e distribuição de organismos edáficos em área de Caatinga na Paraíba, Brasil. 2006. 161 f. Tese (Doutorado em Solos e Nutrição de Plantas) Universidade Federal da Paraíba, Areia, 2006.

SOUTO, P. C. et al. Características químicas da serapilheira depositada em área de Caatinga. Revista Caatinga, Mossoró, v. 22, n. 1, p. 264-272, 2009.

SOUZA, B. V. Avaliação da sazonalidade da deposição da serapilheira em RPPN no semiárido da Paraíba, PB. 2009. 29 f. Monografia (Graduação em Engenharia Florestal) - Universidade Federal de Campina Grande, Patos, 2009.

SOUZA, J. A.; DAVIDE, A. C. Deposição de serapilheira e nutrientes em uma mata não minerada e em plantações de Bracatinga (Mimosa scabrella) e de Eucalipto (Eucalyptus saligna) em áreas de mineração de bauxita. Cerne, Lavras, v. 7, n. 1, p. 101-113, 2001.

STATSOFT. STATISTICA (data analysis software system), version 7. [s. 1.]: Statsoft, 2004.

VELOSO, H. P.; RANGEL FILHO, A. L. R.; LIMA, J. C. A. Classificação da vegetação brasileira adaptada a um sistema universal. Rio de Janeiro: IBGE, Departamento de Recursos Naturais e Estudos Ambientais, 1991. $123 \mathrm{p}$.

VIERA, M.; SCHUMACHER, M. V. Deposição de serapilheira e de macronutrientes em um povoamento de acácia-negra (Acacia mearnsii De Wild.) no Rio Grande do Sul. Ciência Florestal, Santa Maria, v. 20, n. 2, p. 225-233, 2010.

VIERIA, M. et al. Deposição de Serapilheira e Nutrientes em Plantio de Eucalyptus urophylla $\times$ E. globulus. Floresta e Ambiente, Seropédica, v. 3, n. 21, p. 327-338, 2014.

VITAL, A. R. T. et al. Produção de serapilheira e ciclagem de nutrientes de uma floresta estacional semidecidual em zona ripária. Revista Árvore, Viçosa, MG, v. 28, n. 6, p. 793-800, 2004. 